\title{
Removal of Industrial Cement in the External Auditory Canal Through Three-Dimensional Reconstruction of the Temporal Bone and Transcanal Canaloplasty
}

\author{
Min Jae Kim, Sung Hee Bae, Sung Min Lee, and Jun Ho Lee \\ Department of Otorhinolaryngology-Head and Neck Surgery, School of Medicine, Hallym University, Chuncheon, Korea
}

측두골 3 차원 영상과 외이도성형술로 제거된 외이도 내 시멘트 조각 1 예

김민재 · 배승희 · 이성민 · 이준호

한림대학교 의과대학 이비인후-두경부외과학교실

\author{
Received September 12, 2016 \\ Revised November 16, 2016 \\ Accepted November 18, 2016 \\ Address for correspondence \\ Jun Ho Lee, MD, PhD \\ Department of Otorhinolaryngology- \\ Head and Neck Surgery, \\ School of Medicine, \\ Hallym University, \\ 77 Sakju-ro, \\ Chuncheon 24253, Korea \\ Tel $+82-33-240-5181$ \\ Fax $+82-33-241-2909$ \\ E-mail zoonox@nate.com
}

Removing of foreign bodies in the external auditory canal is commonly observed in the otorhinolaryngologic field. Sometimes the size of some materials might change after being embedded in the canal; in such situation, debulking procedures are usually performed to reduce the size of the materials stuck there. But if it is hard to shrink the materials' size, we should consider other procedures. Here we present a minimized procedure utilized to remove nettlesome fragments of industrial cement via 3-dimensional reconstruction of temporal bone computed tomography and partial canaloplasty through transcanal approach.

Korean J Otorhinolaryngol-Head Neck Surg 2018;61(4):208-11

Key Words 3D computed tomography · External auditory canal · Foreign body.

\section{서 론}

외이도의 이물은 이비인후과영역에서 주로 보는 질환이다. 단순한 외이도 이물은 흡입기(section)나 마이크로포셉(microforcep)으로 쉽게 제거가 가능하다. 하지만 개방형 유양 돌기삭개술(canal down mastoidectomy)을 시행하였거나 외 이도의 굴곡이 있는 경우처럼 외이도의 해부학적 구조가 정 상적이지 않은 경우, 외이도에서 이물을 제거할 시에 어려움 이 발생할 수 있다. 특히 이물이 외이도 안에서 팽창하는 재 질이나 변형되는 재질이라면 더욱 제거 시 어려움이 발생할 수 있다. 예로써, 보청기착용 전 귀본(ear mold)을 제작할 시 사용하는 인상제(impression material)가 개방형 유양돌기

This is an Open Access article distributed under the terms of the Creative Commons Attribution Non-Commercial License (http://creativecommons.org/licenses/by-nc/4.0) which permits unrestricted non-commercial use, distribution, and reproduction in any medium, provided the original work is properly cited.
삭개술을 받은 환자에서 빠지지 않는 경우를 들 수 있다. 이 러한 경우에는 일반적으로 현미경하에서 외이도 이물을 부 분적으로 잘라 내어서, 이물의 부피를 줄여 제거하는 방식을 사용하게 된다. 이러한 방식은 신경외과에서 뇌종양 제거시 에 좁은 공간에서 주변을 다치지 않고 제거하는 용적 축소절 차(debulking procedure) 방식으로, 이과영역에서는 진주종 (cholesteatoma)에 각화상피가 꽉 차있을 때, 주로 사용하고 있는 수술방식이기도 하다. 하지만, 병변(lesion)이 제거될 수 있는 입구가 좁은 경우에서 이렇게 병변의 재질이 단단한 경 우에는, 입구를 넓히는 방식을 고려하여야 한다. 저자들은 건축을 할 때 사용하는 시멘트(cement)가 외이도 안에서 굳 은 상태로 내원한 환자를 경험하고 제거하였기에 이를 문헌 고찰과 함께 보고하며, 진단 시 3차원 측두골 단층촬영의 활 용도 및 이를 제거하는 간단한 수술방식을 소개하고자 한다. 


\section{증 례}

49세 남자 환자가 2개월 전 공사현장에서 우연히 좌측 외이 도 안으로 건축용 시멘트의 파편이 들어가는 사고를 당했다. 이후 이충만감 이외에 특별히 불편감을 호소하지 않고 지내 다가 최근 이물 제거를 위해 본원에 내원하였다. 고막의 형태 및 외이도의 형태는 이상이 없어 보였고 반대측과 비교해 봐 도 특이 소견은 관찰되지 않았다. 외이도에서 고막과 접하는 부위쪽에 시멘트 재질의 이물이 관찰되었으며(Fig. 1A), 처음 에는 외래에서 미세현미경하에 제거를 시도하였다. 하지만 시 멘트의 변연부위에서 일부 부서지는 현상은 발생되었지만 주 변의 외이도의 피부조직의 손상이 유발되어 출혈이 악화되었 다. 그리고 마이크로픽(micro-pick, right angled)을 이용하여 제거를 이물 안쪽에서부터 빼내는 방식을 통해 제거를 시도 하였지만, 외이도 안쪽에서 단단한 저항이 손끝에 느껴졌으 며, 이물의 위치를 관상단면에서 시계움직임 방향(coronal plan, clockwise rotation)으로 돌리면서 제거하려고 하였으 나 고막의 위쪽부분에 이물이 접촉되어 이소골의 손상가능 성이 높아져, 제거시술을 중단하였다.
정확한 이물의 외이도 내 위치에 대한 정보가 필요하다고 판단하여, $3 \mathrm{D}$ 측두골 단층촬영을 시도하였다(Fig. 2). 단층촬 영 축면(axial view)상 이물이 고막바로 옆에 위치하였으며, 형태학적 특성상 외이도 내측의 후벽에 걸려 있는 상태임을 확인하였다. 이와 같은 구조는 $3 \mathrm{D}$ 재건 시에 외이도 내측의 후하단부위에만 국한되어 있는 것을 확인하였다(Fig. 2B, black arrow). 본 증례에서 보여지는 $3 \mathrm{D}$ 사진은 중이강 내에 서 외이도를 보는 이미지로 구성되었다.

$3 \mathrm{D}$ 측두골 단층촬영에서 얻은 정보를 가지고, 외이도 내 이 물 제거술을 부분마취하에 시행하였다. 경외이도 접근법으로 시행되었으며, 외이도 입구가 좁은 형태였기에 2번 이경(speculum, \# 2, $5.5 \mathrm{~mm}$ )을 이용하였다.

외이도 피판(meatal flap)을 기존 고막성형술에서 사용하는 방식보다 적게 들어올린 뒤, $0.8 \mathrm{~mm}$ 다이아몬드 드릴(diamond drill, $0.8 \mathrm{~mm}$ of burr size)을 이용하여 이물이 걸려 있는 외이 도 내측의 후방하단부위를 조심스럽게 제거하여 턱을 제거하 였다(partial canaloplasty). 드릴을 사용할 시에는 이경을 삽입 하지 않고, 검지로 이주(tragus)를 앞으로 당기면서 엄지와 중 지로 이개(auricle)를 뒤로 당기는 방식으로 현미경하 드릴작
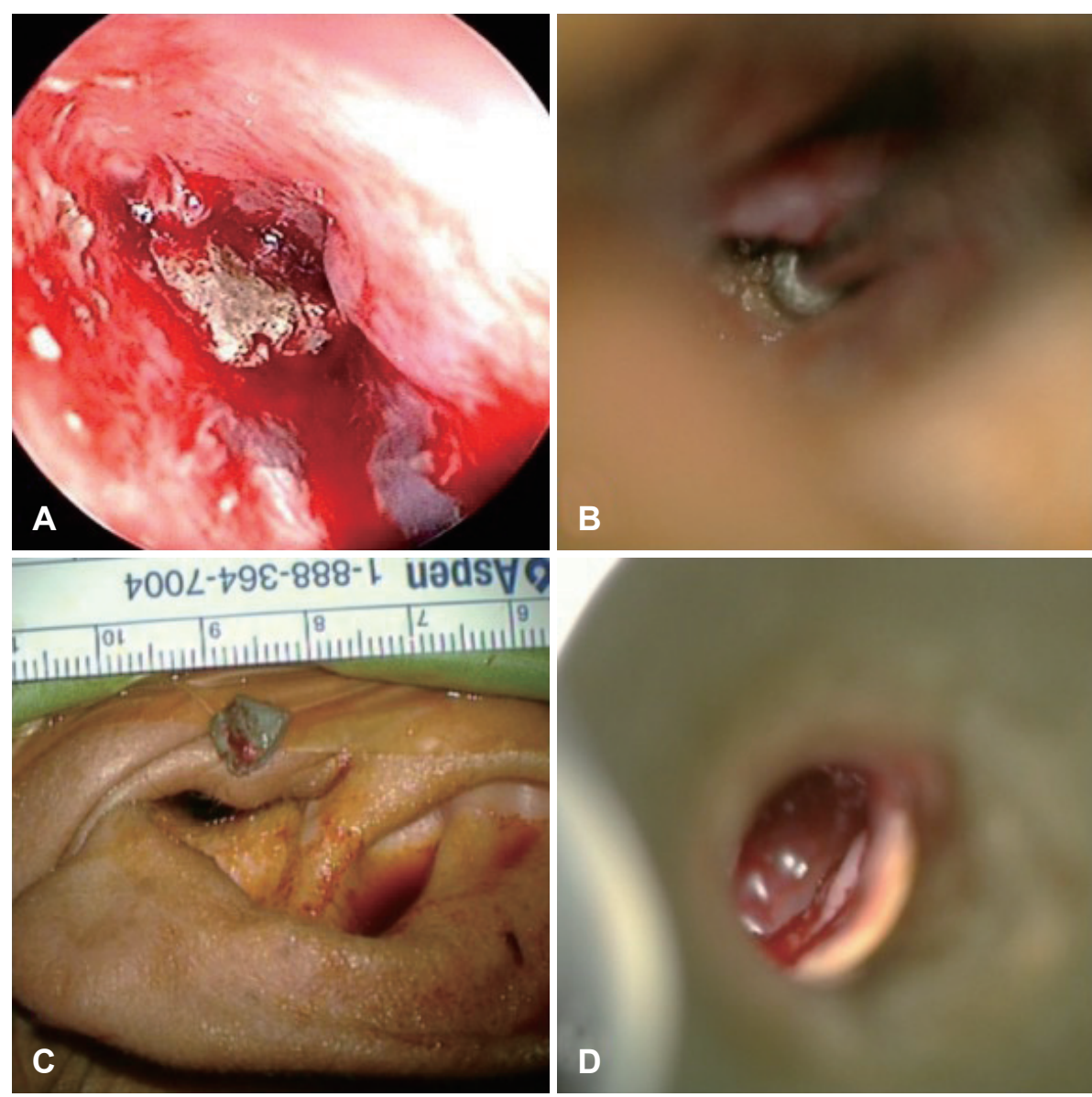

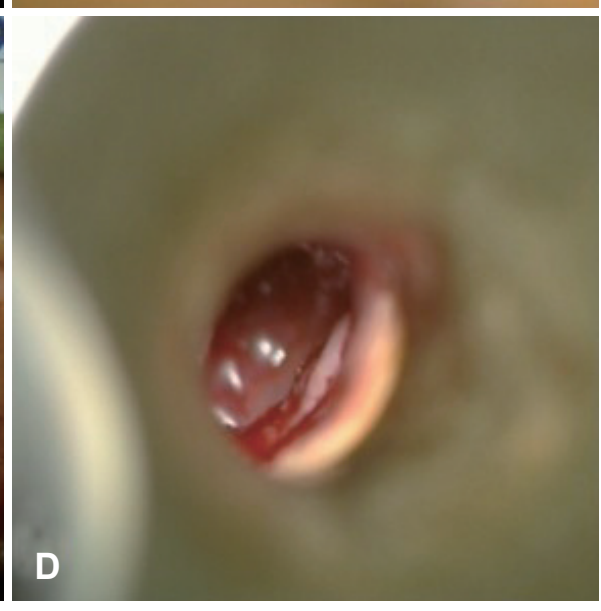

Fig. 1. Otoscopic view of the left ear showing a fragment of industrial cement stuck to external auditory canal (A). Surgical view showing canal drilling via trascanal approach $(0.8 \mathrm{~mm}$ diamond burr) (B). Removed cement fragment, $0.8 \mathrm{~cm}$ length (C). Relatively intact tympanic membrane (D). 

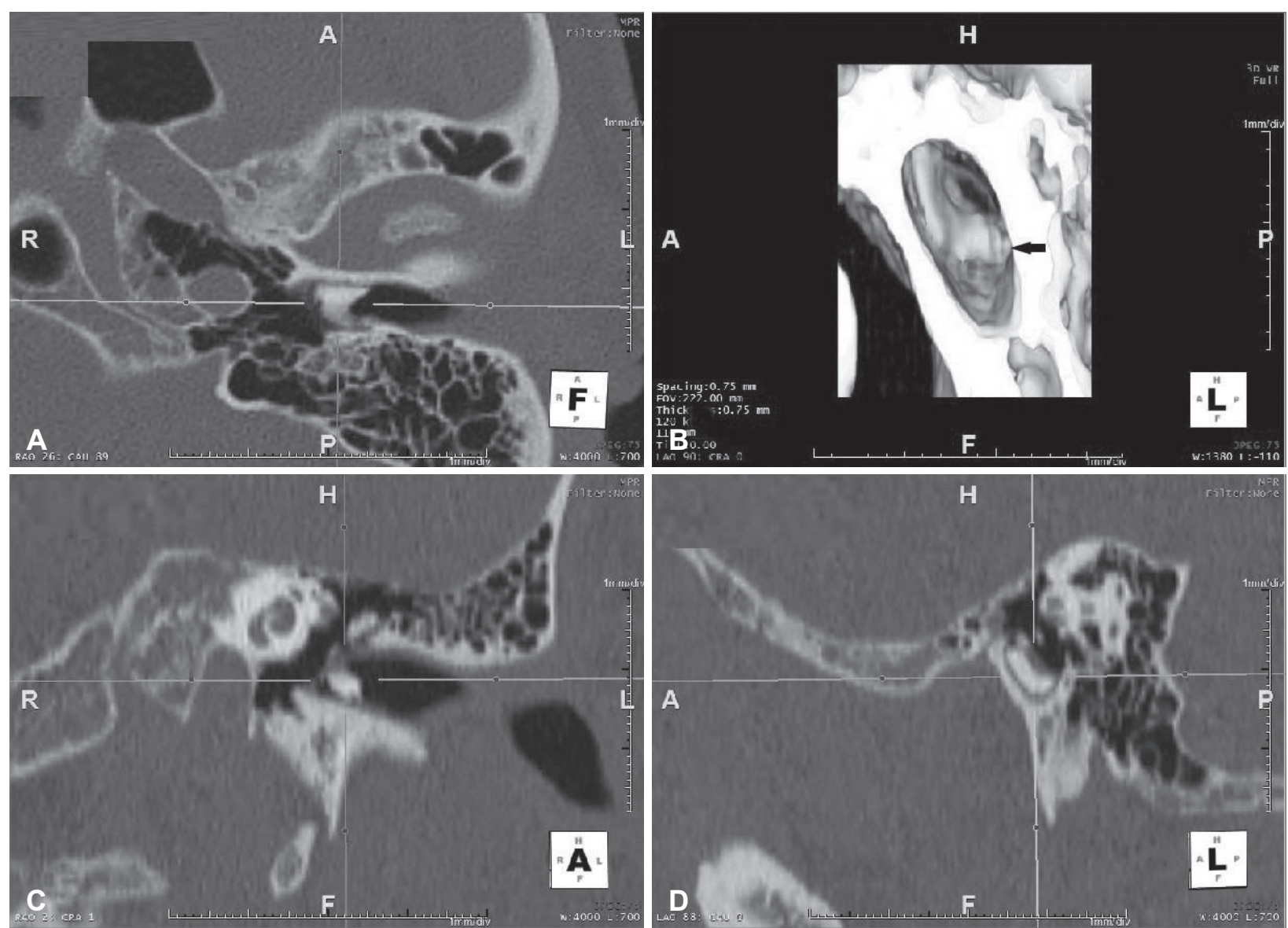

Fig. 2. Axial view (A) 3D reconstructive computed tomography image showing the fragment of cement stuck at the posteroinferior wall of the external auditory canal (black arrow) (B). Coronal view (C) sagittal view (D).

업을 시행하였다(Fig. 1B).

상기 방식을 통해 이물은 제거되었다. 외이도피부에 일부 스 크래치(scratch)가 발생되었고, 2개월간의 외이도 이물로 인해 추골부위에 미세한 육아종(tinny granulation), 고막부위의 불 라(bulla) 소견이 관찰되었지만 중이강으로 외상이 진행된 소 견은 관찰되지 않았다(Fig. 1D). 외이도피판을 다시 원래 위치 에 놓은 뒤 외이도를 젤폼(gelform)으로 충전한 뒤 수술을 종 료하였다. 본 수술에 걸린 시간은 20분이었으며, 수술과정에 피부절개는 필요하지 않았다. 외이도의 시멘트 이물의 크기는 $0.8 \mathrm{~cm}$ 였다(Fig. 1C).

\section{고 찰}

외이도는 사람에 따라 형태가 다양하다. 굴곡이 있는 경우 도 있으며, 크기의 다양성은 여러 연구자들에 의해 보고되고 있다. ${ }^{1,2)}$ 이비인후과 의사들은 외이도를 통해 고막의 소견을 보고 관찰하게 되며, 특히 고막성형술이나 이소골성형술을 시행하게 될 때에는 외이도의 형태 및 크기에 따라 수술접근
방식을 경외이도 수술법, 이내 수술법, 이개후 수술법 중 하나 를 결정하게 된다.

최근 수술방식에 대한 전체 임상 영역의 관심은, 얼마나 환 자에게 비침습적으로 수술을 하는가에 초점이 맞추어져 있 다. 이는 이비인후과영역에서도 활발히 진행되고 있는데 예를 들면, 로봇을 이용한 수술(daVinci robotic system)은 최근 전체 수술 분야에서 적응증 확대를 시도하고 있으며 이비인 후과영역에서도 두경부 분야 중심으로 활발히 연구되고 있 다. ${ }^{3)}$ 또한, 이과영역에서도 내시경하 고막성형술과 같은 새로

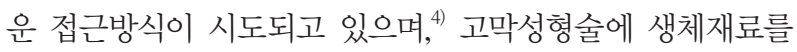
활용한 대체연구와 같은 환자에게 최소한의 침습을 통한 접 근방법을 적용하려는 시도가 활발히 진행되고 있다. ${ }^{5)}$

이와 같은 시대적 흐름에 따라, 본 증례에서 보여주고자 하 는 저자들의 제안은 다음과 같다. 첫 번째로, 외이도 이물의 재질 특성을 고려하여 적절한 조치를 취하는 것이 필요하다. 기존의 교과서에서 제시한 것처럼, 크기가 작은 이물인 경우에 는 쉽게 제거할 수 있다. 유생이물인 경우에는 적절한 조치를 취한 뒤 제거할 수 있다. 하지만, 기존의 치료 개념을 벗어나 
는 외이도의 변형 상태나 예상치 못한 이물을 제거해야 되는 상황이 발생된다면 적절한 치료에 대한 계획을 수립하여야되 며, 그 계획에서 중요한 점은 환자에게 비침습적인 방식을 구 상하여 선택해야 하는 점이다. 두 번째는, $3 \mathrm{D}$ 단층촬영의 이 과분야에서의 활용도이다. 현재 이비인후과 분야에서 안면 외상과 같은 질환인 경우 $3 \mathrm{D}$ 재건이 활발히 사용되어지고 있 다. ${ }^{6}$ 하지만 이과분야에서는 그 적용분야가 아직은 미흡한 실 정이다. 이소골의 결손이나 유양돌기 삭개술의 수술 전 이미 지 트레이닝을 위한 3차원 재건이 가능한 분야로 시도될 수 있 지만, 해상도의 한계성과 측두골 안에 위치하고 있는 한계성 때문에 이 기술을 접목시키기에는 쉽지 않은 점이 있다. 하지 만, 본 증례와 같이 특정상황일 경우에는 활용할 수 있는 점 을 보아서, 이과분야에서도 시작단계지만 활용될 수 있는 가 능성을 보여준다. 세 번째는, 경외이도 수술법 적용대상의 확 대이다. 보편적으로 외이도를 넓히는 수술인 외이도골성형술 (canaloplasty)을 시행할 시에는 이개후 수술법이 주로 사용되 고, 술자에 따라 이내 수술법이 사용되기도 한다. 특히 외이 도가 좁은 경우에는 더욱 이개후 수술법으로 접근하는 것이 합당하다. 최근 외이도 접근 시에 내시경을 이용한 수술방식 이 소개되고 있는데, 이는 외이도골성형술까지도 가능성이 있 음을 최근 Kozin 등ㄱㅇㅣ 외골종증(exostoses) 환자에서 가능 함을 소개하였다. 내시경을 이용한 수술기법이 이과영역에서 소개되고 있지만, 3 차원적 원근감을 술자에게 보여줌으로써
외이도의 3차원적 구조를 이해하는 데에 있어서의 큰 이점이 있는 미세현미경의 장점을 따라가기에는 아직 부족해 보인다. 특히 외이도골성형술 및 외이도성형술(meatoplasty)인 경우 외이도의 직경이 좁다 하더라도 측두골 3차원 영상을 통한 외이도의 정확한 측정을 통한다면 최소침습을 이용한 경외 이도 수술법이 가능함을 저자들은 보고하는 바이다.

\section{REFERENCES}

1) Noh H, Lee DH. Direct measurement of ear canal volume in a pediatric population: can we explain its individual variation in terms of age and body weight? Int J Pediatr Otorhinolaryngol 2012;76(5): 658-62.

2) Ikari Y, Katori Y, Ohtsuka A, Rodríguez-Vázquez JF, Abe H, Kawase $\mathrm{T}$, et al. Fetal development and variations in the cartilages surrounding the human external acoustic meatus. Ann Anat 2013;195(2):128-36.

3) Park YM, Kim SH. Feasibility of robotic surgical system in the field of head and neck surgery. Korean J Otorhinolaryngol-Head Neck Surg 2009;52(8):641-7.

4) Huang TY, Ho KY, Wang LF, Chien CY, Wang HM. A comparative study of endoscopic and microscopic approach type 1 tympanoplasty for simple chronic otitis media. J Int Adv Otol 2016;12(1):28-31.

5) Lee JH, Kim DK, Park HS, Jeong JY, Yeon YK, Kumar V, et al. A prospective cohort study of the silk fibroin patch in chronic tympanic membrane perforation. Laryngoscope 2016;126(12):2798-803.

6) Li Y, Yang X, Li D. The application of three-dimensional surface imaging system in plastic and reconstructive surgery. Ann Plast Surg 2016;77 Suppl 1:S76-83.

7) Kozin ED, Remenschneider AK, Shah PV, Reardon E, Lee DJ. Endoscopic transcanal removal of symptomatic external auditory canal exostoses. Am J Otolaryngol 2015;36(2):283-6. 